\title{
Perception of patients after bariatric surgery on quality of life
}

\author{
Lívia Moreira Barros ${ }^{1}$, Maria Girlane Sousa Albuquerque Brandão*1, Amanda de Oliveira Barbosa ${ }^{1}$, Natália Ângela \\ Oliveira Fontenele ${ }^{1}$, Maria Aline Moreira Ximenes ${ }^{1}$, Nelson Miguel Galindo Neto ${ }^{2}$, Joselany Áfio Caetano ${ }^{3}$ \\ ${ }^{1}$ State University Vale do Acaraú, Sobral, Ceará, Brazil \\ ${ }^{2}$ Federal Institute of Pernambuco, Caruaru, Pernambuco, Brazil \\ ${ }^{3}$ Federal University of Ceará, Fortaleza, Ceará, Brazil
}

Received: October 17, 2018

Accepted: December 25, 2018 Online Published: January 14, 2019

DOI: $10.5430 /$ jnep.v9n5p32

URL: https://doi.org/10.5430/jnep.v9n5p32

\begin{abstract}
Objective: This study aimed at understanding the perception of bariatric patients about their Quality of Life (QoL) after bariatric surgery.

Methods: Descriptive and qualitative study performed at a reference hospital for bariatric surgery in the State of Ceara/Brazil. Subjects were 27 patients who were experiencing postoperative and data collection was made from interviews with semi-structured document. Data was subjected to qualitative content analysis, which allowed the emergence of categories: "In searching for a healthier life"; "The weight cycling villain and failure in other treatments"; "The meaning of quality of life and a reflection of obesity in daily life"; "The effects on quality of life of individuals after bariatric surgery". The project was approved by the Ethics Committee (CEP 538/2011).

Results: For most patients, QoL is defined as having a healthy life with the possibility of exercising without tiring easily, being able to eat properly, performing better at work and having a more active social life.

Conclusions: Thus, it is seen that bariatric surgery was effective on QoL improvements on self-esteem, self-care, work performance, leisure and social relationships.
\end{abstract}

Key Words: Morbid obesity, Bariatric surgery, Quality of life

\section{INTRODUCTION}

Obesity is a chronic disease of multifactorial etiology characterized by excessive accumulation of body fat. There are genetic, environmental, behavioral, cultural and emotional factors that contribute to the appearance of this type of eating disorder. It represents a public health problem in developed and developing countries due to the growth in the number of overweight and obese people, which overwhelms the public health systems. ${ }^{[1-3]}$
Thus, in view of the worldwide epidemic of obesity in individuals of all age groups, bariatric surgery appears as a treatment and possibility for a healthier life with higher quality and resolution of associated comorbidities, as well as providing new perspectives of life for obese individuals. ${ }^{[1,3,4]}$ It should be indicated when a person presents a serious risk of health problems related to the degree of obesity and when more conservative interventions (diet, exercise and medication) were ineffective for weight control. To perform surgery,

\footnotetext{
*Correspondence: Maria Girlane Sousa Albuquerque Brandão; Email: girlane.albuquerque@ yahoo.com.br; Address: Street L 04, 428, Jerônimo de Medeiros Prado, Sobral, Ceará, Brazil.
} 
the obese must have $\mathrm{BMI} \geq 40 \mathrm{~kg} / \mathrm{m} 2$ or $\mathrm{BMI} \geq 35 \mathrm{~kg} / \mathrm{m} 2$ if there is any comorbidity. ${ }^{[1,5,6]}$

The expected results of bariatric surgery are weight loss, and resolution or betterment of comorbidities, such as: systemic arterial hypertension, diabetes mellitus, coronary disease, dyslipidemia, infertility and sleep apnea. In addition, there will be an improvement in the quality of life of these patients, based on dietary education, physical activity, smoking cessation and alcoholism, improving self-esteem and social relations, among other factors. These changes contribute to the minimization of psychosocial and physical problems, improving aspects related to Quality of Life (QoL). ${ }^{[1,4,7]}$

The QoL topic after bariatric surgery has been the subject of study by many researchers, since it has become a useful variable to determine the overall impact of diseases and medical treatments from the perspective of the individual, and its measure is potentially useful for research and clinical practice to demonstrate the potential benefit of therapeutic interventions. Although it is widely demonstrated that bariatric surgery offers the short- and long-term improvement in quality of life, there may be variations of postoperative changes for each patient in each of the aspects that involve the quality of life, as physical, psychological, social and sexual. ${ }^{[4,5,8]}$

The definition of quality of life adopted for the present study will be the one developed by the group of scholars of the World Health Organization (WHO), given its characteristics of subjectivity and multidimensionality, namely: "perception of the individual's position in life in the context of the culture and value system in which it lives and in relation to its goals, expectations, standards and concerns". [9] In this context, when associating quality of life with obesity, it is necessary to analyze other dimensions such as health-related quality of life, weight-related quality of life and the impact of being obese in aspects such as body image, sexual functioning and socialization. ${ }^{[10]}$

The negative impact of obesity on individuals' quality of life is one of the main motivators for seeking bariatric surgery as a solution for overweight. Thus, it is pertinent to evaluate the impact of this surgical treatment on aspects that encompass the quality of life of these individuals, especially in aspects such as sociability, emotional stability and lifestyle that are the critical points to obtain a better quality of life.

Understanding how patients perceive the changes that occur with daily bariatric surgery may favor the planning of interventions that enhance postoperative adaptation and long-term surgical outcomes.

In light of the above, this research is justified by the possibility of generating knowledge among the scientific community, which will help professionals to understand patients' experiences after bariatric surgery and to develop programs that improve the health and quality of life of these patients. Therefore, this study aimed to understand the perception of bariatric patients about their quality of life after surgery.

\section{METHOD}

\subsection{Study design}

This is a descriptive research with a qualitative approach performed from July to September of 2017 in a reference hospital in the State of Ceará in the accomplishment of bariatric surgeries by the Sistema Único de Saúde (SUS).

\subsection{Inclusion and exclusion criteria}

The subjects of the study were selected in a non-probabilistic way, following the criterion of empirical saturation, defined by Bardin, ${ }^{[11]}$ which occurs when the information becomes repeated or the addition of new data is minimal to submit to the procedures. In this manner, 27 patients undergoing bariatric surgery who were in the late postoperative period, minimum of three months, met the following inclusion criteria: being over 18 years old and enrolled in the institution's bariatric surgery program.

\subsection{Data collection}

Data were collected, individually, through guided semistructured interview divided into two parts. The first part contained demographics variables (sex, age, marital status, education and monthly household income). The second one contained questions related to quality of life as: "What reasons led you to seek bariatric surgery as a treatment?"; "For you, what is quality of life?"; "Do you believe that your quality of life has changed after surgery? Why?" and "Is there anything you did not do before the surgery and now you do? If so, what is that?".

\subsection{Data analysis}

Obtained data were submitted to the qualitative content analysis proposed by Bardin (2008). As a consequence, we pre-analyzed and exploited data, through exhaustive readings, following the steps of codification and categorization in the search for construction of thematic categories. Then, inference was made from the obtained data and using as theoretical reference the material available on bariatric surgery and quality of life, as well as scientific publications about obesity.

Analysis of the content of interviews allowed the grouping of the interviewees' perceptions, according to similarity and frequency, regarding the quality of life, establishing the categories of the study. 


\subsection{Ethical considerations}

In compliance with the Helsinki Declaration regulating research on humans, participants were informed of the study's objectives and were assured of the confidential nature of the data and anonymity, so that the identification of the study individuals is presented following the coding by flower names, being this choice made due to the transformation that these patients suffer after the accomplishment of the surgical procedure, characterizing an allusion to the process of awakening of a rose.

Data collection was performed only after their agreement in the research participation, using the Informed Consent Term. The project was approved by the Research Ethics Committee of the Institution, and approved according to protocol no. $588 / 2011$.

\section{RESUlts}

Twenty-seven people undergoing bariatric surgery participated in this study, of which 23 were female and four were male. The predominant age group was 31 to 40 years old (44.4\%), with a mean age of 39.7 years old. As for marital status, four were divorced, 21 married and two unmarried. Regarding schooling, there was a predominance of complete high-school education among the individuals. The monthly family income ranged from zero to eight minimum wages, averaging 2.4 wages per person, prevailing between 1 and 5 wages/month.

From data analysis process, four categories were identified: 1) In search of a healthier life; 2) Failure with other treatments and the appearance of the weight cycling; 3) The meaning of Quality of Life and the reflection of obesity in the daily life of individuals; 4) Impact on the quality of life of individuals after bariatric surgery.

\subsection{In search of a healthier life}

When questioned about the reasons that led them to perform bariatric surgery, it was observed that many patients stated that they sought this treatment as the solution for comorbidities arising from overweight in order to improve their health and reduce risks of early mortality. Others have decided to undergo the procedure because of the prejudice and discrimination suffered by being obese and to increase self-esteem.

"Because I was feeling very heavy ... Suffering discrimination. I did not use to live, I vegetated ..." Sunflower

"It was because of my health problems. It was because of high blood pressure. I always fainted. And because of arthrosis. I was already walking on a crutch. And there is also the self-esteem issue. It looks ugly and useless..." Jasmine

"That weight was bothering me a lot and my blood pressure was too high ..." Rose "I was giant and I was sure I was going to die early. I think it would only be solved by the surgery ..." Orchid

It is perceived by the reports that being an obese causes numerous damages to the quality of life of these individuals. From the moment they realize that they will not be able to live a healthy life with conventional treatments, the search for bariatric surgery becomes the last hope of losing weight and achieving an improvement in physical, mental, social and emotional well-being.

\subsection{Failure with other treatments and the appearance of the weight cycling}

Another motivating cause for bariatric surgery was the occurrence of weight cycling, which stems from the failure to maintain weight loss with nutritional diets, nutritional education, use of anti-obesity drugs, increase in physical activity, as well as behavior modification and lifestyle. Usually, the obese experience this process of weight cycling after returning to their usual habits after rigorous treatments as pointed in the following statements:

"I was too fat. It was out of control. I could not control my weight ..." Daisy "Because I tried everything in life and despaired. I was very obese ..." Amaryllis

"I'm tired of dieting. After losing 2 or $3 \mathrm{~kg}$, I get double weight .." Hyacinth

It is observed that some treatments like restrictive dieting and the use of drugs to lose weight end up becoming villains over time, since they contribute to a weight loss in a short period of time and, after the abandonment of these, the lost pounds are recovered quickly, which is called a weight cycling.

Is this manner, the experience of the weight cycling is a stressful one for the obese, whose problem often intensifies due to the use of risky strategies that intensify the weight gain, predisposing people to more health deseases, making it difficult to reach a healthier life. Consequently, all the positive results achieved with the previous treatment are lost, which generates frustration, hopelessness and uncontrolled weight.

\subsection{The meaning of Quality of Life and the reflection of obesity in the daily life of individuals}

From the patients' reports, it was verified that the meaning of quality of life was related to having a healthy life, which 
in the interviewees' perception included: having a balanced diet and living well with life. This last report encompasses the ability to carry out daily work, such as taking care of the house, working with excellence and being able to practice physical activities with the proper physical layout.

"To be well with life and be understood. To have a healthy life and eat well ..." Daisy

"It is to live better and healthier. To go for a walk and not get tired." Snapdragon

"It is to be able to own my house, to be able to exercise my profession." Cherry

"Being willing to do something and actually do it. Performing the day-to-day work." Carnation "It's being human. No one was calling me anywhere. I did not use to take a bus. It is to be able to enjoy the good things..." Orchid

"It's how I am now. Eating well and practicing physical activity." Hyacinth "It is to be able to move because in the old days I moved with difficulty and people kept laughing at me." Lily

It was verified that obesity interferes in people's quality of life, negatively affecting the relations of the subjects with themselves and with others around them, being the condition of human being questioned by one of the patients of the study. This makes us reflect on the need for psychological support to address the barriers placed in the lives of these individuals. It is necessary that the professional enables active listening and counseling in order to provide means for a solution of the problems with obesity.

Impact on the quality of life of individuals after bariatric surgery. Achieving the desired weight tends to improve self-perception and the attainment of QoL improvement by transforming these people's lives. There is significant improvement, in physical, psychic and emotional health, contributing to the individual's return to social life. From a new lifestyle after surgery, the person rediscovers new habits of life and new pleasures. A simple crossing of legs, wearing shoes, going to the beach and dancing becomes a great achievement.

"Nowadays I can walk in the mall and go to the beach ..." Daisy

"I love crossing my legs without difficulty ..." Gardenia

"I can wear my shoes ..." Lily

"It's changed $100 \%$. My routine has changed a

lot. I started going out, I started eating well and exercising." Tulip

"Nowadays I am happy. I used to feel unhappy.

I'm happy to get dressed and to buy clothes. I look more into the mirror. I want to make myself up ..." Daisy

"Yes. Because now I can do things I did not do before. I wear clothes and I feel good." Hyacinth

"It's changed $100 \%$. Because I lived inside a prison not knowing about it. I had no social life, I did not go on dates ... I used to be prejudiced." Blue Rose

In this survey, bariatric surgery had a very positive result on patients' quality of life. Many have stated that everything has changed and that they feel more satisfied today. These changes are reflected in simple attitudes such as practicing physical activity, being astonished in front of the mirror, enjoying dressing, leaving home, sleeping well and being able to relate to other people.

The loss of excess weight and the adoption of healthy habits reflects not only in the emotional state, but also in the achievement of the improvement of comorbidities associated with obesity. In this study, subjects reported blood pressure control, remission of medication intake and resolution of infertility:

"Yes. Radically. It changed a lot already. My blood pressure is controlled and I will not take any more medicine." Jasmine

"It is currently great. You see that obesity itself has a lot of prejudice. Employment is easier. I was able to get pregnant again." Gardenia "Yes, a lot. I can work without getting tired. I can walk everywhere. I want to hang out ..." Antigonon Leptopus

"Yes. Now I can work. I sleep well. I feel free of diseases that I was almost sure I had." Field Flower

"Yes. Everything has changed. At work, at marriage. I practice physical activity, I relate well to people and I became social.” Poppy

Work performance is also made possible with weight loss. The recognition of their competence and the increase of their visibility in the team are considered important for the satisfaction of workers. Thus the individual feels more motivated to perform his duties and to stand out in the work environment.

The following statements present the patients' reports on quality of life aspects such as self-esteem and social and loving relationship:

"My self-esteem is a thousand times better. We feel alive." Amaryllis

"Yes. Everything has changed. Even my way of 
thinking and acting. My self-esteem is on top !" Sunflower

"I go out more often nowadays. I like to take pictures. I like going out to dance!" Cherry "I've changed my appearance. I love to buy clothes. I'm more vain!” Blue Rose “Dating, flirting, conquering someone ..." Jasmine

After bariatric surgery, participants reported improvement in self-esteem and, consequently, in their qualities of life. Improvement in love relationships is also strengthened by changes in the body and mind of the individual.

From the reports, it is possible to conclude that the weight loss favored by the surgical procedure allowed improvement in important aspects related to the quality of life as self-care, increased self-esteem, better socialization and better work performance. With bariatric surgery, the patients revealed that they were more interested in being in love with other people, were more able to practice physical activity and maintained the dietary routine during the day in order to favor greater weight loss at long term.

\section{Discussion}

Morbid obesity is associated with increased physical limitations, body pain, fatigue and depression that contribute to deterioration of quality of life. ${ }^{[10]}$ Obese people often report problems such as anxiety, depression, eating disorders and self-esteem issues resulting in social isolation, feelings of discrimination in personal and professional life, failure in social relationships, family and love. ${ }^{[2,12,13]}$

Searching to improve the quality of life and the physical state, the obese seek several conventional treatments, however, few conventional treatments for obesity are effective for sustained weight loss at long term. ${ }^{[14]}$ Initially, the treatment for obesity considers behavior change like changes in lifestyle, healthy eating and increasing physical activity being the most emphasized recommendations. ${ }^{[15]}$ Drug therapy is recommended for obese individuals who have comorbidities, whose dietary modifications and exercise for five years have had no effect. ${ }^{[16]}$

However, failures in conventional treatments are very common in obese people, as reported by the study participants, as they seek for quick responses to weight loss and end up suffering from weight cycling, which is characterized by cyclical weight variations resulting from weight loss and/or fast weight gain after treatments that did not have a desirable effect. By stopping the treatment, there will be greater accumulation of fat and, consequently, weight gain. Over the decades, repeated events of the weight cycling may in- crease the risk of impairment of the cardiovascular and renal systems, notably. ${ }^{[17]}$

Faced with failure and frustration with other treatments, then the unbridled search for normalization of the body through bariatric surgery appears as the fastest resource for the possibility of being a new person. Diante do fracasso e da frustração com outros tratamentos, a busca desenfreada pela normalização do corpo, a cirurgia bariátrica aparece como alternativa efetiva e duradoura para a redução do peso e melhora geral da saúde. ${ }^{[18]}$ It is common in obese patients to be extremely concerned about appearance, resulting in significant social, psychological and occupational impairment. ${ }^{[19]}$

For some individuals, surgery is capable to offer a new life perspective to patients with morbid obesity and weight loss can mean acceptance, social success and happiness. ${ }^{[20,21]}$ This is reflected in the possibility of having a healthy life with the maintenance of social life and the recovery of a functional body. ${ }^{[22]}$

For others, surgery presents itself as a means to meet the aesthetic criterion of thinness as a subjective and socially established body pattern, and as a strategy to overcome the failure of conventional treatments already performed and the search for quality of life. ${ }^{[23]}$ In this manner, many people resort to bariatric surgery to achieve an improvement in the quality of life in biopsychosocial aspects, representing the return to social life, the improvement of health and self-esteem. ${ }^{[5]}$

Some patients believe that bariatric surgery is a mechanical way of overcoming the problem of overweight, but patients need to be made aware of the importance of active participation in the care process. These individuals should understand that bariatric surgery is a useful tool for weight loss, but patient engagement in changes in lifestyle is required.

The knowledge of successful cases among acquaintance or relatives and their support, especially those with whom they maintain an affective-sexual bond, stimulate and reinforce the decision to perform the surgery. ${ }^{[23]}$ These positive results, such as the improvement or resolution of several health problems, make bariatric surgery the most desired treatment for morbidly obese patients, since it allows weight loss and optimization of health status.

The subjects in this study report that weight loss has been associated with improvements in health-related quality of life and these results corroborate with the findings of a study conducted in the United States with 2,458 patients undergoing bariatric surgery who reported changes in quality of life with positive impact on reducing body pain, physical functioning and fitness for walking. ${ }^{[7]}$ 
According to study subjects, bariatric surgery is considered to minimize health problems, decrease the risk of diseases associated to obesity and increase longevity. It is known that obesity causes several health damages, among which type II diabetes, hypertension, hyperlipidemia, obstructive sleep apnea, coronary disease, atherosclerosis, several types of cancer and bad Quality of Life (QOL). ${ }^{[6]}$ The presence of comorbidities that negatively impact quality of life, such as hypertension and diabetes, are associated with a greater search for bariatric surgery. ${ }^{[10]}$

It generates expectations and concretizes changes that, in the picture of obesity, are valid because they allow a positive reorganization of the lifestyle. ${ }^{[24]}$ Subjects who underwent the surgery perceive the treatment as an opportunity to be reborn, which means to return to the search for normality, to improve the associated clinical conditions and to improve QoL, the latter represented by aspects of self-esteem, physical condition, social condition, capacity work and sexual performance. ${ }^{[25]}$ Benefits provided by weight loss after surgery are also present in the reports since the current condition that patients are experiencing provides an improvement in quality through the elimination of prejudice, nutritional education and exercising. However, success of surgical treatment depends on the individual's involvement, especially in relation to eating behavior. ${ }^{[26]}$ Thus, it is important that the patient is always questioned and oriented about changes in lifestyle, which includes balanced eating and regular practice of physical activity.

A qualitative study carried out in Romania with 34 patients revealed that the improvement in quality of life was reported by the majority of patients with an impact on sports performance, increased libido and quality of sexual relations, motivation to walk and adherence to healthy eating. However, some patients showed intolerance to foods such as meat, eggs, sweets and milk, which decreases satisfaction related to bariatric surgery. ${ }^{[3]}$ The importance of periodic evaluation of the aspects that potentiate or impair the quality of life of patients undergoing bariatric surgery is highlighted. Excess skin, food intolerance, and frustration about expected results may be detrimental to the patient's well-being. Thus, it is necessary that the professional verifies if this surgical treatment was effective for better quality of life and health status of the patient.

\section{Conclusion}

In view of the above, it was possible to observe that bariatric surgery proved to be effective in changes in the quality of life of individuals, enhancing self-esteem, self-care, performance in work, leisure and social relationships. Most patients defined QoL as having a healthy life with the possibility of practicing exercises without getting tired easily, being able to feed themselves properly, to perform better at work and to have more active social life.

Multiprofessional team should work during the entire intraoperative period in order to inform and guide patients about the surgical treatment of morbid obesity, as well as its implications and repercussions on the individual's lifestyle. The importance of nutritional education and the practice of physical activities in the postoperative period is highlighted as a way to achieve the desired results with surgery.

It is necessary to establish measures for the prevention and control of obesity and overweight, even in the third decade of life, through the guidance of patients regarding obesity treatments, thus contributing to the empowerment of the subjects involved, favoring the development of skills that will help them to change behaviors, overcome difficulties and clear doubts.

In this perspective, Nursing must adapt to the educational strategies in health to the education of patients, aiming to interfere effectively in health, in favor of these patients' quality of life. The presence of low income among patients undergoing bariatric surgery may hinder access to a healthy diet and the purchase of vitamin supplements necessary for the maintenance of the obtained results, for the rest of the patient's life.

It is worth mentioning that it is fundamental to carry out future research aimed at understanding this patient experience after surgery, considering that changes occur in all aspects of biopsychosocial and the multiprofessional team must be prepared to provide this assistance, requiring studies that enable increasing knowledge about these situations in order to facilitate the creation of strategies that improve clinical practice.

\section{CONFlicts of InTEREST Disclosure}

The authors declare that there is no conflict of interest.

\section{REFERENCES}

[1] Efthymiou V, Hyphantis T, Karaivazoglou K, et al. The effect of bariatric surgery on patient HRQOL and sexual health during a 1-year postoperative period. Obes Surg. 2015; 25(2): 310-8. PMid:25085222 https ://doi .org/10.1007/s11695-014-1384-x

[2] Neff KJ, Olbers T, le Roux CW. Bariatric surgery: the challenges with 
candidate selection, individualizing treatment and clinical outcomes. BMC Med. 2013. https//doi .org/10.1186/1741701511-8

[3] Mirica RM, Ionescu M, Mirica A, et al. Quality of Life Assessment After Bariatric Surgery-a Single-Center Experience. Indian Journal of Surgery. 2018; 80(5): 435-441. https://doi.org/10.1007/ s12262-017-1624-0

[4] Brunault P, Ducluzeau PH, Bourbao-Tournois C, et al. Food Addiction in Bariatric Surgery Candidates: Prevalence and Risk Factors. Obes Surg. 2016; 26(7): 1650-3. PMid:27107892 https: //doi.org/10.1007/s11695-016-2189-x

[5] Major P, Matłok M, Pędziwiatr M, et al. Quality of Life After Bariatric Surgery. Obes Surg. 2015; 25(9): 1703-1710. PMid:25676156 https : //doi .org/10.1007/s11695-015-160 1-2

[6] Anvari M, Lemus R, Breau R. A Landscape of Bariatric Surgery in Canada: For the Treatment of Obesity, Type 2 Diabetes and Other Comorbidities in Adults. Can J Diabetes. 2018; 42(5): 560-567. PMid:29724616 https://doi.org/10.1016/j.jcjd.2017.12 .007

[7] King WC, Chen JY, Belle SH, et al. Change in Pain and Physical Function Following Bariatric Surgery for Severe Obesity. JAMA. 2016; 315(13): 1362-71. PMid:27046364 https ://doi.org/10.1 $001 /$ jama. 2016.3010

[8] Sockalingam S, Hawa R, Wnuk S, et al. Psychosocial predictors of quality of life and weight loss two years after bariatric surgery: Results from the Toronto Bari-PSYCH study. Gen Hosp Psychiatry. 2017; 47: 7-13. PMid:28807141 https://doi.org/10.1016/j. genhosppsych.2017.04.005

[9] Organização Mundial de Saúde (OMS). Physical status: the use and interpretation of anthropometry. Genebra: World Health Organization. 1995.

[10] Sarwer DB, Hanson AJ, Voeller J, et al. Obesity and Sexual Functioning. Curr Obes Rep. 2018; 7(4): 301-307. PMid:30220074 https : //doi.org/10.1007/s13679-018-0319-6

[11] Bardin L. Análise de conteúdo. 19ª Ed. Lisboa/Portugal: Edições 70. 2008.

[12] Galli F, Cavicchioli M, Vegni E, et al. Ten years after bariatric surgery: Bad quality of life Promotes the need of psychological interventions. Frontiers in Psychology. 2018; 9(9): 1-5. https: //doi.org/10.3389/fpsyg. 2018.02282

[13] Canetti L, Bachar E, Bonne O. Deterioration of mental health in bariatric surgery after 10 years despite successful weight loss. Eur J Clin Nutr. 2016; 70(1): 17-22. PMid:26197876 https : //doi .or $\mathrm{g} / 10.1038 / \mathrm{ejcn} .2015 .112$
[14] Silva PT, Patias LD, Alvarez GC, et al. Perfil de pacientes que buscam a cirurgia bariátrica. Arq Bras Cir Dig; 2015 dez; 28(4): 270-3.

[15] Yanovski SZ. Weight Management in Adults With Obesity: What Is a Primary Care Clinician to Do? JAMA. 2018; 320(11): 1111-1113. PMid:30422282 https://doi.org/10.1001/jama.2018.1103 1

[16] Taglietti RL, Riepe SB, Maronezi TB, et al. Avaliação psicológica para cirurgia bariátrica: práticas atuais. RBONE. 2018; 12(69): 101109.

[17] Dulloo AG, Schutz Y. Adaptive Thermogenesis in Resistance to Obesity Therapies: Issues in Quantifying Thrifty Energy Expenditure Phenotypes in. Curr Obes Rep. 2015; 4(2): 230-40. PMid:26627218 https://doi.org/10.1007/s13679-015-0156-9

[18] Flores CA. Avaliação psicológica para cirurgia bariátrica: práticas atuais. ABCD Arq Bras Cir Dig. 2014; 27(Suplemento 1): 59-62.

[19] Toma T, Harling L, Athanasiou T, et al. Does Body Contouring After Bariatric Weight Loss Enhance Quality of Life? A Systematic Review of QOL Studies. Obes Surg. 2018; 28(10): 3333-3341. PMid:30069862 https : //doi.org/10.1007/s11695-018-332 3-8

[20] Oliveira APSV, Ribeiro MA. Fatores conjugais e familiares que dificultam a perda de peso em mulheres obesas. Saúde \& Transformação Social. 2013; 4(3): 65-74.

[21] Penno A, Kolankiewcz ACB, Rosanelli CSP, et al. Cirurgia bariátrica: uma opção para melhorar a qualidade de vida. Rev de Enfer UFPE on line. 2012; 6(5): 794-800.

[22] Castanha CR, Ferraz AAB, Castanha AR, et al. Avaliação da qualidade de vida, perda de peso e comorbidades de pacientes submetidos à cirurgia bariátrica. Rev Col Bras Cir. 2018; 45(3): e1864.

[23] Nascimento CAD, Bezerra SMMS, Angelim EMS. Vivência da obesidade e do emagrecimento em mulheres submetidas à cirurgia bariátrica. Estudos de Psicologia. 2013; 18(2): 193-201. https : //doi.org/10.1590/S1413-294X2013000200004

[24] Poulsen L, McEvenue G, Klassen A, et al. Patient-Reported Outcome Measures: BODY-Q. Clin Plast Surg. 2019; 46(1): $15-$ 24. PMid:30447824 https://doi.org/10.1016/j.cps.2018 .08 .003

[25] Hachem A, Brennan L. Quality of life outcomes of bariatric surgery: a systematic review. Obes Surg. 2016; 26(2): 395-409. PMid:26494369 https : //doi .org/10.1007/s11695-015-194 $0-z$

[26] Tae B, Pelaggi ER, Moreira JG, et al. O impacto da cirurgia bariátrica nos sintomas depressivos e ansiosos, comportamento bulímico e na qualidade de vida. Rev. Col. Bras. Cir. 2014; 41(3): 155-160. 